https://helda.helsinki.fi

Veterinary students' experience of stress during educational transition phases and its effect on self-regulation

\title{
Laakkonen, Juha
}

Routledge - Taylor \& Francis Group

2017

Laakkonen , J \& Nevgi , A 2017 , Veterinary students' experience of stress during educational transition phases and its effect on self-regulation . in E Kyndt, V Donche , K Trigwell \& S Lindblom-Ylänne (eds), Higher Education Transitions : Theory and Research . , 10 , New Perspectives on Learning and Instruction, Routledge - Taylor \& Francis Group , Abingdon, Oxon , pp. 155-171 . https://doi.org/10.4324/9781315617367-12

http://hdl.handle.net/10138/309650

https://doi.org/10.4324/9781315617367-12

unspecified

acceptedVersion

Downloaded from Helda, University of Helsinki institutional repository.

This is an electronic reprint of the original article.

This reprint may differ from the original in pagination and typographic detail.

Please cite the original version. 
Veterinary students' experience of stress during educational transition phases and its effect on self-regulation

Juha Laakkonen, University of Helsinki, Department of Veterinary Biosciences, P.O. Box 66, 00014 University of Helsinki, Finland

Anne Nevgi, University of Helsinki, Centre for Research and Development of Higher Education, P.O. Box 900014 University of Helsinki, Finland

\section{Transitions and students' experiences of stress in studies of veterinary medicine}

The transitions that successful undergraduates need to negotiate include the way they relate to their chosen field of study, the changes in their learning strategy, and the way they perceive themselves (Hussey \& Smith 2010). The major challenges facing veterinary students during transition 
stages include the new type and constantly changing subject matter, the experience of a temporary dissonance between their preferred learning strategies and the perceived demands of the new and changing learning environments (Vermunt \& Verloop 1999, 2000; Raidal \& Volet 2009). Other recognized transitions in veterinary medicine include the transition from preclinical to clinical studies and from clinical studies into veterinary profession (e.g. Raidal \& Volet 2009).

Educational transitions can also be a risk factor for students' well-being and motivation (TuominenSoini et al. 2012) and expose students to stress. Recurrent stress is a common experience for veterinary medicine students as they are expected to cover overwhelming amount of information (Reisbig et al. 2012), adjust to the demanding curriculum, and to cope with new type of learning environments such as dissection halls, hospital facilities, farms and abattoirs with occasionally unpleasant sights, smells, and emotions (Collins \& Foote 2005, Kogan et al. 2005, Strand et al. 2005, Hafen et al. 2006, Robotham \& Julian 2006, Sutton 2007, Gardner \& Parkinson 2011, Laakkonen \& Nevgi 2014, see Powers 2002). Examinations and the subsequent wait for results is also cause for concern for many students (Robotham \& Julian 2006) as well as the transition into less didactic teaching methods of university teaching (Abouserie 1994, Radcliffe \& Lester 2003, Laakkonen \& Nevgi 2014). Gibbs et al. (2004) have suggested that the process of transition can amount to a transformation of the students themselves. It has been suggested that as far as is practical, the organization of the curricula and teaching in higher education should be based upon the (planned) major transitions which students undergo (Hussey \& Smith 2010).

Most first-year veterinary students are well-motivated, highly competitive and individualistic learners (Raidal \& Volet 2009, Thurman et al. 2009, Parpala et al. 2011) who may find it difficult to adjust to learning environments that encourage cooperative learning (Salomäki et al. 2014) which is favoured by teachers because students are expected relatively quickly to achieve high levels of 
autonomy and social skills as a preparation for their future profession. As veterinary students often do not routinely use any coping strategies and demonstrate poor reflective skills (Williams et al. 2005, Ruohoniemi \& Lindblom-Ylänne 2009, Mikkonen \& Ruohoniemi 2011), it may be difficult for them to adjust their learning strategy to the university demands. If they additionally receive poor exam scores, they may experience significant stress, especially if this is associated with low selfesteem (Abouserie 1994). Veterinary students experiencing high academic stress were more likely to report a higher level of depression and anxiety symptoms, and showed decreased life satisfaction (Reisbig et al. 2012). Finnish first-year veterinary students have ranked issues relating to the curriculum as the most important stress factor, with an imbalance in assessment requirements, the number of lectures and overall requirements of the course as contributing factors (Ruohoniemi \& Lindblom-Ylänne 2009; Laakkonen \& Nevgi 2014).

Stress unique to veterinary students has received relatively little attention apart from a number of dissertations on the topic (Gelberg \& Gelberg 2005) showing that veterinary students must process a large amount of information in a short period of time. They must learn, for example, about the biology, diagnosis and treatment of many species of animals, with little time or skills to reflect on their notes or non-required reading (Gelberg \& Gelberg 2005). The overload and time management issues can be especially challenging for veterinary students because most of them have not detected deficits in these skills before veterinary school but instead have excelled in school.

Many veterinary students also experience significant amount of subjective stress (Strand et al. 2005) partly because many of them are keen animal lovers but a central part of their professional work is euthanasia of pet and production animals as a way to humanely treat animals (Fraser \& Quine 1989). 


\section{Transitions and self-regulation in learning in veterinary medicine}

While successful programs have been designed to familiarize students with practical matters of the university life (Yorke 2000; McInnis 2001; Pitkethly \& Prosser 2001), little is often done to promote transition to the more independent and active learning strategies of higher education. In general, selfregulated students show high levels of deep understanding, critical evaluation and optimism in studies which in turn relate to general increased well-being, decreased experiences of stress and increased study success (Eronen et al. 1998; Heikkilä et al. 2012).

Differences in self-regulation in learning (SRL) of students entering the veterinary program cause additional challenges for first-year veterinary students and their teachers, and the nature of this transition may vary between countries depending on the educational background of the new veterinary students. This poses challenges for university education, as differences in SRL have been shown to influence the quality of learning and student achievement in a significant manner (Pintrich and Zusho, 2007; Richardson et al. 2012). According to Pintrich (2004) SRL is comprised of four components: (a) forethought, planning and activation; (b) monitoring; (c) control; and (d) reaction and reflection. Students' experience of stress during their studies is related to their skills to monitor and control the learning process and to reflect on their learning (Laakkonen \& Nevgi 2014).

In Finland, where our study was carried out, most first-year veterinary students have previous university credits and a few students even have completed other degrees (Laakkonen \& Nevgi 2014). Most North American first-year veterinary students have completed four years of undergraduate education and are usually at a different development stage than undergraduate students (Gelberg \& Gelberg 2005). Furthermore, results of one US study showed that 71 per cent of students did not enter veterinary school immediately upon completion of the first undergraduate degree but also had majored in biology or related subjects before becoming first-year veterinary students (Kedrowicz et 
al. 2015). Clearly, such students experience less stress and are likely to be much better adapted to the university level studies at the veterinary school than students transiting directly from secondary education. Some veterinary schools have a significant number of foreign students that makes the firstyear student cohort even more heterogeneous (Tötemeyer et al. 2012), and create demands for additional support (Cho \& Yu 2014).

Several authors (Ryan et al. 2004, Ruohoniemi et al. 2010, Chigerwe et al. 2011) have reported on the approaches and learning strategies of veterinary students at various stages of veterinary programs. The perception of high workloads, the use of previous exam files as a method for studying, and examinations that are exclusively based on material provided in lecture notes were positively associated with the surface learning approach. The fact that veterinary students often do not have the time (due to high workload), or do not know how to reflect on their learning (Ryan et al. 2004; Ruohoniemi et al. 2010) creates a constant challenge for veterinary educators especially in transition phases

\section{The curriculum and transitions of the bachelor degree programme of the Finnish Veterinary Medicine Education}

In Finland, the Faculty of Veterinary Medicine of University of Helsinki offers all the training and education in veterinary medicine. The six-year programme comprises of a (preclinical) three-year Bachelor of Veterinary Medicine degree (180 ECTS) and a (clinical) three-year Licentiate Veterinary Medicine degree (180 ECTS). The aim of the curriculum is to provide the students with competence to work independently as a veterinary professional, and capabilities to continue their education to meet the future demands (Faculty of Veterinary Medicine, Mikkonen \& Ruohoniemi 2011) 
First-year students are supported in their transition to veterinary medicine studies by asking them to write a personal study plan, and to participate in orientation to studies at the beginning of the first semester. During the first study year students complete integrated courses on veterinary anatomy, physiology and biochemistry and language courses (Finnish, Swedish, and English) as well as and studies in information and communication technology. Most of the students have previous university credits from some of these topics, or they are familiar with the topics through their secondary education studies. Medical terminology, which is used throughout the studies, is a major stress factor for students at this stage. During the second year, the subject studies comprise of animal hygiene including genetics, parasitology, microbiology and immunology, pathology, and meat inspection techniques. In addition, students participate in four weeks of extramural farm practice (6 ECTS), and complete a course focusing on veterinary ethics and animal welfare. The subject studies of the third and final year of bachelor studies comprise of epidemiology, pharmacology and toxicology, and meat inspection. Students are also introduced to the clinical work and the ethics of veterinary medicine and animal welfare. Finally, students deepen their knowledge of scientific work and write a Bachelor's Thesis (6 ECTS). Thus, during their first three study years, students experience a wide variety of lectures, group works, practical and dissection exercises, laboratory analyses, and training with live animals.

\section{Aims of the study}

The aim of the study reported in this chapter was to investigate how learning strategies, time management and factors related to well-being influence the students' transition from secondary school or previous university studies into veterinary studies, and from preclinical studies into clinical studies during their first three years of the Finnish six-year veterinary programme. For 
readers interested in the transition from the clinical studies into the veterinary profession, see Gilling \& Parkinson (2009). In an attempt to address the lack of longitudinal studies on transitions in veterinary education (Robotham \& Julian 2006), views of the students who participated in our previous study (Laakkonen \& Nevgi 2014) were revisited before they made the transition from basic into clinical studies.

Our specific research questions were

1. What type of differences can be distinguished in veterinary students' experienced stress between their first and third study year? What are the factors that stress students at their transit into academic studies of veterinary medicine? What are the factors that stress students at their transit into clinical studies of veterinary medicine?

2. In what ways students' experienced stress, prior university level studies and selfregulation in learning are related, and what type of differences in these relations can be distinguished in the beginning and the end of the bachelor degree programme?

\section{Methods}

\section{Data gathering and subjects}

The follow-up study was carried out in two phases and the first author collected the data. At the first phase of the study (autumn 2012), data were collected from the first-year students (64 females, 5 males) after the completion of the osteology course by asking students to fill out a questionnaire (see Laakkonen \& Nevgi 2014). Forty-five students (42 females, 3 males, $65 \%$ response rate) participated in this first phase of the study. At the second phase of the study, data were collected by asking the same students, who were now almost at the end of their third study year (in March 2015), to complete a questionnaire during an orientation course into the clinical anatomy and physiology. 
Forty-six students (44 females, 2 males, $67 \%$ of response rate) participated in this second phase of the study.

At the first phase of the study, the respondents' ages ranged from 19 to 35 years (mean 22), and at second phase of the study the respondents ages ranged from 22 to 38 years (mean 25). Nineteen students $(41 \%)$ responded that they had also participated in the first phase of the study. The rest did not answer the question concerning their previous participation in the study. Thus the student groups of first-year and third-year students consist of partly the same respondents and partly different students who may or may have not participated in the both phases of study.

On both occasions students were given ten minutes to complete the questionnaire. Besides oral instructions while administrating the questionnaire, the students were informed in advance by a separate email that the questionnaire and results would be handled anonymously and confidentially, and that it would be used for educational research to improve the preclinical curriculum of the veterinary program. Participation was voluntary. Students could answer anonymously and they were not rewarded for their cooperation.

\section{Materials}

The questionnaire consisted of open-ended questions, and instruments to measure the experienced stress (Elo et al. 2003) and learning strategies (Lonka et al. 2008; Niemi et al. 2003). The questionnaire was a part of the feedback system approved by the faculty council.

As for their demographic background, students were asked to report their year of birth, gender, and at the first phase of study, students were asked to report the number of university credits gained before the beginning of veterinary studies. At the second phase of the study, the students were also 
asked to state particularly stressful periods during their preclinical studies, and whether they had participated in the previous study.

As a measure for the stress students had experienced, they were asked whether (and if when) they had experienced feelings of anxiety, nervousness or had trouble sleeping (cf. Elo et al. 2003) during their preclinical studies (for definitions of stress see Lazarus \& Folkman 1984; Ross et al. 1999; Aherne 2001; Elo et al. 2003; Kogan et al. 2005) and rate their experience by applying the 5-scale Likert type scale: 1 = Totally disagree, 2 = Disagree, $3=$ Neutral, $4=$ Agree, $5=$ Totally agree. In order to measure factors related to students experience of stress, students were asked to rate five statements concerning the effect of other concurrent courses, the test score, and the amount of new subject matter as well as the demanding learning goals on the level of stress they experienced by applying the 5-scale Likert type of scale (see Lonka et al. 2008).

On self-regulation in learning, students rated nine statements (modified from Lonka et al. 2008 and Niemi et al. 2003) concerning self-monitoring of learning (3 items), persistency (3 items) and reflection on learning (3 items) (Table 1).

\section{Analyses}

Initial descriptive statistics, namely frequency distributions, means, and standard deviations for all variables, were generated using SPSS PASW Statistics Version 18.a. This software was also used in all other statistical analyses of this study.

We examined the structure of the three scales measuring self-regulation in learning by explorative factor analysis (Principal Axis Factoring, Varimax rotation) separately for data of the first and the third study years. The factorial structure of self-regulation in learning differed slightly between the 
first and third study year as the item I try to accommodate my own style of studying so that it would match with the requirements of each course loaded on different factors (See Table 2). For the purposes of further analyses, the item was not included in the sum variable Self-monitoring of learning (See Table 1).

The Cronbach's alpha coefficients were extracted to test the internal reliability of the scales of Study Stress $(4$ items $)(\mathrm{T} 1=.74 ; \mathrm{T} 2=.59)$, Self-monitoring of learning $(\mathrm{T} 1=.81 ; \mathrm{T} 2=.74)$, Persistency $(\mathrm{T} 1=.66 ; \mathrm{T} 2=.57)$, and Reflection on learning $(\mathrm{T} 1=.54 ; \mathrm{T} 2=.58)$. (see Table 1$)$

Changes in students' experiences of stress, time-management and learning strategies between the first and third study year were examined by calculating means and standard deviations of these variables. Correlations between variables were tested with the nonparametric Spearman's two-tailed correlation analysis because of the relatively small sample size.

\section{Results}

Students' experiences of stress at the beginning and the end of their bachelor degree studies

The mean stress level reported by students at the beginning of studies was $2.89(S D=1.09)$ and at the end of preclinical phase $3.96(S D=1.05$, Table 1$)$ indicating that students became more stressed as their studies progressed. According to the students the strongest stress factor related to their studies was the demanding learning goals of the courses (First study year $M=3.07, S D=1.12$; Third study year $M=3.80, S D=1.06$, Table 1$)$. The increase in this stress factor indicates that the students experience that their courses were becoming increasingly challenging as their studies progressed. In the very beginning of studies, concurrent courses were not a significant source of stress (First study year $M=2.33, S D=1.13$, Table 1 ). However, concurrent courses had become the 
second strongest factor to cause stress by the third study year $(M=3.47, S D=1.31$, Table 1$)$. In the beginning of their studies, students were more concerned about their grades $(M=2.98, S D=1.27)$ than during their third study year $(M=2.47, S D=1.16$, Table 1$)$. Third-year students experienced more stress from non-academic factors $(M=3.07 ; S D=1.18)$ compared to the first-year students $(M=2.20 ; S D=1.27$, Table 1$)$.

Insert table 1 here.

The students were divided into two groups (19-21 years of age and 22-35 years of age) to examine whether the students' age in the beginning of veterinary studies was related to their experiences of stress. We identified no differences between the age groups either during the first or second phase of the study.

For our first research question, we asked students to name one factor related to the new type of learning content or material causing for them academic stress. In the beginning of their studies, students reported the following factors: the need to learn medical terminology ( 23 students), the need to understand what is important (two students), rapid progression of the studies (one student), and the overall demands of the university studies (one student). As for the third-year students, 20 (43\%) students stated the spring term of the second year as particularly stressful due to courses that had assessments requiring recall of a large number of specific terminology and details, or due to uncertainty of assessment requirements. Two students mentioned oral presentations as a cause for stress, and one student experienced increased stress prior to exams. Also, one student had experienced group work, and another student the studying in farm context as stressful. Interestingly, no one named the end of a term, when students are often visible tired, as particularly stressful. 
We also screened individually the answers of those 19 students who had stated that they had participated in the first study (Laakkonen \& Nevgi 2014). All 19 students associated their selfreported stress levels with the demanding learning goals and new subject matters as shown also by the data including all students (Table 2). However, the disappearance of the fear of getting a low grade indicates that third-year students are beginning to see their studies as an entity leading to a profession and not as separated exams, or they have higher self-efficacy by the third study year. Third-year students are also setting learning goals for themselves (Table 1) which may be an indication that students understand which skills and knowledge entities are needed as they prepare themselves for clinical studies and the veterinary profession.

Insert Table 2 here.

In contrast to the first study year, stress did not correlate significantly with prior credits $(r=.21)$ or concurrent courses $(r=.24$, Table 2$)$ during the third study year indicating that once students get used to studying at the higher education context, the significance of prior studies as a stressreducing factor diminishes.

\section{Relationship between prior university level studies, the experienced stress and self-regulation in learning}

Our second research question focussed on what kind of relationships can be identified between prior university level studies, experienced stress and self-regulation in learning in the beginning of veterinary studies, and how these relationships may have changed by the third year of studies.

The factor structure of self-regulation in learning differed slightly between the first and the third study year. At the first study year, the item measuring student's aim to accommodate his/her 
learning approach to the requirements of each course loaded on the first factor of self-monitoring on learning (Table 2) indicating that at the first-year students aim to adjust their learning approach to meet the demands of course schedule. By the third study year, this item loaded on the factor "Reflection on learning" indicating that students had learned to reflect on how their learning approach met the requirements of a particular course (Table 2).

At the transition to veterinary studies, prior university level studies had a negative correlation both to the subjective stress experience $\left(\mathrm{r}_{\mathrm{s}}=-.32\right)$ and to the study stress $\left(\mathrm{r}_{\mathrm{s}}=-.30\right)$ revealing that prior study experience helps students to cope with the demands of veterinary medicine courses. Prior university level studies had a positive correlation with persistency $\left(r_{s}=.30^{*}\right.$, Table 3$)$. By the third study year, the correlations between prior university level studies and students' stress experience had decreased, and the only positive correlation between prior level university studies was with the reflection on learning $\left(\mathrm{r}_{\mathrm{s}}=.35\right)$. In the beginning of veterinary studies, stress due to studying had a negative correlation with persistency $\left(r_{s}=-.56\right.$, Table 4$)$.

Insert table 3 here.

Insert table 4 here.

Based on the comments by the respondents to the open-ended questions, students improved their self-monitoring of learning over time. This may reduce stress but many third-year students still mentioned the lack of time due to non-academic factors and concurrent courses as a factor relating to well-being. The correlation of stress with demanding learning goals $\left(.31^{*}\right)$ and new subject matters $\left(.35^{*}\right)$, which also correlated with each other $\left(.44^{* *}\right)$, as well as the replies to the openended questions on time management show that extensive learning goals and the different teaching methods of various subject matters challenge both the time management and learning strategy 
approaches of also third-year students. In contrast to first-year students, third-year students also experienced significant stress $(r=.42 * *)$ because they had to give up studying on difficult topics (probably due to time management issues).

\section{Discussion and educational implications of the study}

During the first transition from school or previous studies into veterinary medical education, the students experienced stress most strongly with the demanding learning goals of the courses and the new type of subject matters (see also Laakkonen \& Nevgi, 2014). At this stage, non-academic stress was not a major factor. In the beginning of veterinary studies, previous university level studies were negatively related to subjective stress experience, and positively correlated to persistency in learning indicating that students with prior study experience have an advantage over their less experienced peers.

By the time of the second transition at the end of preclinical studies, the effect of previous studies on subjective stress experience had disappeared. However, prior university level studies correlated with the reflection on learning at this second transition phase indicating that the students with more study experience may have refocused from study performance into reflections of their own actions and motives in learning. At the second transition, students used their time effectively while studying. Students with higher academic stress also reflected more on their learning indicating that while students gain more experience in studies of veterinary medicine, they also mature and take more responsibility of their learning.

In the beginning of veterinary studies, stress did not correlated strongly with non-academic factors, but at the second transition phase, these other factors increasingly influenced students' experience of stress. In this study students were not asked to name these factors, but factors relating to 
financial, work-related and personal relationships are often mentioned (Gelberg \& Gelberg 2005; Strand et al. 2005) as causes for stress. Previous surveys however, show no differences in causes or effects of stress between year cohorts (Collins \& Foote 2005, McLennan \& Sutton 2005). Also Kogan et al. (2005) reported that there were no differences in the non-academic stressors veterinary students face based on gender or year in school.

Results of McLennan \& Sutton (2005) show that students had difficulties adjusting to a new course despite being well accustomed to university life. They also reported that the causes for academic stress did not vary significantly between first and third-year veterinary students. In the present study older students and those with prior credits still had an advantage over the less mature students because the former were able to use their time efficiently $(r=.32 *)$ and reflect on their learning strategy $\left(r=.46^{* *}\right)$. In contrast to the results of previous studies done in Finland (Ruohoniemi \& Lindblom-Ylänne 2009, Mikkonen \& Ruohoniemi 2011) and elsewhere (Williams et al. 2005), results of this study show that by the third study year veterinary students have changed their focus from coping with the study schedule and demands of the courses to reflection on learning. A previous study of third-year Finnish veterinary students showed that unorganized students applying a deep approach experienced the most workload and pressure of progressing in their studies according to the predetermined timetable (Ruohoniemi et al. 2010, see also Mikkonen \& Ruohoniemi 2011). Of the factors impeding the study progress the commonly mentioned were lack of motivation, stress, fatigue, and similarly to the results of this study, problems in time management that were underlined by the curriculum overload. High workload due to demanding curriculum is mentioned as a cause for stress in most studies addressing veterinary students (see above).

Based on the results of this study and review of literature, some findings emerge that could be 
implemented on the curriculum to help veterinary students in transitions occurring during the preclinical stage of their studies. The rapidly advancing veterinary curriculums often do not provide time to introduce new students properly to the history of profession, principles of science or the specific nature of various subject matters creating the veterinary profession. This lack of historic perspective does not allow students to relate themselves to their chosen field of study, or the way they perceive themselves as new university and veterinary students. This may lead to lack of motivation (see discussion in Mikkonen \&Ruohoniemi 2011) and stress caused by a transitional misfit (Gibbs et al. 2004; Hussey \& Smith 2010) when students begin to realize how many skills are needed to become a veterinarian. In the interactional model of stress (Aherne 2001) the significant nature of self (Cameron 1999) and the importance of student development, which are central components in successful transitions, are emphasized (Hussey \& Smith 2010). Despite the already overloaded curriculums, we need to find the time to familiarize students with the history and development of veterinary profession, for example as part of tutoring programs prior the actual studies.

The steps taken to tutor students in the first transition stage sets the basis for students' active learning and responsibility of their learning favoured by modern higher education and this should be taken into account in the curriculum by providing extra time for tutoring during the very first courses of the curriculum (and preferably also in each transition period). Besides giving students time to adjust, it allows staff members to have time to complement their role as teachers and researchers by the role of tutors. In the veterinary program of the University of Helsinki students are tutored prior to the beginning of the term in practical matters but no extra time is allowed for the first subject matter courses to familiarize students with the new learning strategies and environments, or professional vocabulary (much of which is used throughout the curriculum) despite the fact that these factors are known to cause stress for the new veterinary students (Laakkonen \& Nevgi 2014; this study). Ideally 
the first courses of each transition period should be taught by teachers who are pedagogically trained for the challenges related to that particular transition.

Alignment of practises should also extend to tutoring done by mature students. Many veterinary schools have active tutoring programs where older students guide new students. Despite not being an expert on pedagogy, student tutors often give specific advice to new students on how to study and prepare for assessments. This may create difficulties for the new students because course structure and content may change from year to year creating entirely new learning entities. This is underlined by the fact that many veterinary medicine faculties actively update their curriculums partly because of the increased pedagogic training for teachers in recent years. The way teachers or students were tutored in their own time is not necessarily the way to prepare new students for their studies or future profession in a rapidly changing world.

Based on the results of this and other studies (Ruohoniemi et al. 2010; Mikkonen and Ruohoniemi 2011) the specific requirements of the diverse subject matters and learning environments challenge both the time management and learning strategies of veterinary students throughout the preclinical studies. It is therefore important that the teaching practises and assessments of various courses throughout the preclinical phase are aligned as far as the specific requirements of each subject matter allow, thus making the instructional experience less stressful for the students. Ryan et al. (2004) has similarly suggested that the tendency to surface learning could be reduced by giving the students clearer objectives, direction, and frequent feedback. Alignment is especially important in veterinary and medical degree programs where learning environments and strategies change many times during the studies.

Many modern teaching methods emphasise the work done by students alone or in groups outside the 
class room, and therefore underline the students' responsibility for their time management. Some students fail to take this into account (this study, J. Laakkonen personal observation) by including too many activities, both academic and other, for their schedule. This may also be one of the reasons why students often see the learning goals of courses as too extensive to cope (see above). It needs to be stated clearly to the students in the beginning of each course, and monitored for the extent to which it is being heard, that autonomy is widely regarded as one of the main goals of education and in order to succeed, students are expected to have increasing role in their learning and time management.

Examinations are a major cause of stress especially in faculties with rapidly advancing and demanding curriculums (Abouserie 1994). Assessment of learning (not to be called tests or exams) should be a continuous every day practice and also include feedback in learning strategies. All procedures likely to diminish stress experienced by students will also help the staff, because stress will often lead to student absence from courses and assessments. Additional or alternative ways to complete learning assignments create considerable amount of extra work for teachers because rapidly advancing veterinary curriculums do allow enough time for these. In many veterinary schools, the diminishing number of staff will add additional pressure.

Finally, the transition for university studies should start in the secondary school in a concrete way. University teaching strives to implement teaching methods that encourage students to be critical thinkers. These are often time-consuming because they may include integration of course material in other disciplines as well as books and articles that challenge students while providing explanations beyond lecture material (Chigerwe et al. 2011). For example, even in the very beginning of university studies students are often given journal articles for additional course material (forming thus partly the extensive learning goals shown above to be one of the causes of stress) but are seldom at this stage given tutoring on how to read and analyse scientific papers. 
Clearly, we need to improve the preparedness of students to read scientific literature.

\section{References}

Abouserie, R. 1994. Sources and levels of stress in relation to locus of control and self-esteem in university students. Educational Psychology 14: 323-330.

Aherne, D. 2001. Understanding student stress: a qualitative approach. The Irish Journal of Psychology 22: 176-187.

Cameron, J. E. 1999. Social identity and the pursuit of possible selves: Implications for the psychological well-being of university students. Group Dynamics: Theory, Research, and Practice 3: 179-189.

Chigerwe, M., IIkiw, J.E. \& Boudreaux, K.A. 2011. Influence of a veterinary curriculum on the approaches and study skills of veterinary medical students. Journal of Veterinary Medical Education 38: $384-394$.

Cho, J. \& Yu, H. 2014. Roles of university support for international students in the United States: analysis of a systematic model of university identification, university support, and psychological well-being. Journal of Studies in International Education 1-17, DOI: 10.1177/1028315314533606.

Collins, H., Foote, D. 2005. Managing stress in veterinary students. Journal of Veterinary Medical Education 32: 170-172.

Elo, A.-L., Leppänen, A. \& Jahkola, A. 2003. Validity of a single-item measure of stress symptoms. Scandinavian Journal of Work, Environment and Health 29: 444-451.

Eronen, S., Nurmi, J.-E. \& Salmela-Aro, K. 1998. Optimistic, defensive-pessimistic, impulsive and self-handicapping strategies in university environments. Learning and Instruction 8: 159-177. Faculty of Veterinary Medicine, University of Helsinki. 2015. Retrieved May 5, 2015 from http://www.vetmed.helsinki.fi/english/

Fraser, A.F. \& Quine, J.P. 1989. Veterinary examination of suffering as a behavioral-linked condition. 
Applied animal Behavior Sciences 23:353-364.

Gardner, D.H. \& Parkinson, T.J. 2011. Optimism, self-esteem, and social support as mediators of the relationships among workload, stress, and well-being in veterinary students. Journal of Veterinary Medical Education 38: 60-66.

Gelberg, S. \& Gelberg, H. 2005. Stress management interventions for veterinary students. Journal of Veterinary Medical Education 32: 173-181.

Gibbs, P., Angelides, P. \& Michaelides, P. 2004. Preliminary thoughts on a praxis of higher education teaching. Teaching in Higher Education 9: 183-194.

Gilling, M.L. \& Parkinson, T.J. 2009. The transition from veterinary student to practitioner: A “make or break" period. Journal of Veterinary Medical Education 36: 209-215.

Hafen, Jr., M., Reisbig, A.M., White, M.B. \& Rush, B.R. 2006. Predictors of depression and anxiety in first-year veterinary students: a preliminary report. Journal of Veterinary Medical Education 33: 432-440.

Heikkilä, A., Lonka, K., Nieminen, J. \& Niemivirta, M. 2012. Relationships between students' approaches to learning, cognitive and attributional strategies, well-being, and study success. Higher Education 64: 455-471.

Hussey, T. \& Smith, P. 2010. Transitions in Higher Education. Innovations in Education and Teaching International 47: 155-164.

Kedrowicz, A.A., Fish, R.E., Hammond, S. 2015. Relationship between anticipatory socialization experiences and first-year veterinary students' career interests. Journal of Veterinary Medical Education 42: 18-27.

Kogan, L.R., McConnell, S.L. \& Schoenfeld-Tacher, R. 2005. Veterinary students and non-academic stressors. Journal of Veterinary Medical Education 32: 193-200. 
Laakkonen, J. \& Nevgi, A. 2014. Relationships between learning strategies, stress and study success among first-year veterinary students during an educational transition phase. Journal of Veterinary Medical Education 41: 284-293.

Lazarus, J. \& Folkman, S. 1984. Students' perceptions of medical school stress and their evaluation of a wellness elective. Medical Education 59: 7-12.

Lonka, K., Sharafi, P., Karlgren, K., Masiello, I., Nieminen, J., Birgegård, G. \& Josephon, A. 2008. MED NORD - A tool for measuring medical students' well -being and study orientations. Medical Teacher 30: 72-79.

McInnis, C. 2001. Researching the first year experience: where to from here? Higher Education Research and Development 20: 105-114.

McLennan, M.W. \& Sutton, R.H. 2005. Stress in veterinary science students: a study at the University of Queensland. Journal of Veterinary Medical Education 32: 213-218.

Mikkonen, J. \& Ruohoniemi, M. 2011. How do veterinary students' motivation and study practices relate to academic success? Journal of Veterinary Medical Education 38: 298-304.

Niemi H, Nevgi A, Virtanen P. 2003. Towards self-regulation in web-based learning. Journal of Educational Media, 28(1):49-71. http://dx.doi.org/10.1080/1358165032000156437.

Parpala, A., Lindblom-Ylänne, S. \& Rytkönen, H. 2011. Students’ conceptions of good teaching in three different disciplines. Assessment \& Evaluation in Higher Education 36:549563.

Pitkethly, A. \& Prosser, M. 2001. The first year experience project: a model for university-wide change. Higher Education Research and Development 20: 185-198.

Pintrich, P.R. 2004. A conceptual framework for assessing motivation and self-regulated learning in college students. Educational Psychology Review 4: 385-408. 
Pintrich, P.R., \& Zusho, A. 2007. Student motivation and self-regulated learning in the college classroom. In P. R. Perr \& J. C. Smart (Eds.), The scholarship of teaching and learning in higher education: An evidence-based perspective (pp. 731-810). New York: Springer

Powers, D.E. 2002. Student perceptions of the first year of veterinary medical school. Journal of Veterinary Medical Education 29: 227-230.

Radcliffe, C. \& Lester, H. 2003. Perceived stress during undergraduate medical training: a qualitative study. Medical Education 37: 32-38.

Raidal, S.L. \& Volet, S.E. 2009. Preclinical students' predispositions towards social forms of instruction and self-directed learning: a challenge for the development of autonomous and collaborative learners. Higher Education 57: 577-596.

Reisbig, A.M.J., Danielson, J.A., Wu, T.-F., Hafen, Jr. M., Krienert, A., Girard, D. \& Garlock, J. 2012. A study of depression and anxiety, general health, and academic performance in three cohorts of veterinary medical students across the first three semesters of veterinary school. Journal of Veterinary Medical Education 39: 341-358.

Richardson, M., Abraham, C., \& Bond, R. 2012. Psychological Correlated of University Students' Academic Performance: A Systematic Review and Meta-Analysis. Psychological Bulletin 138: 353387.

Robotham, D. \& Julian, C. 2006. Stress and the higher education student: a critical review of the literature. Journal of Further and Higher Education 30: 107-117.

Ross, S.E., Niebling, B.C. \& Heckert, T.M. 1999. Sources of stress among students. College Student Journal 33: 312-317.

Ruohoniemi, M. \& Lindblom-Ylänne, S. 2009. Students' experiences concerning course workload and factors enhancing and impeding their learning - a useful resource for quality enhancement in teaching and curriculum planning. International Journal of Academic Development 14: 69-81. Ruohoniemi, M., Parpala, A., Lindblom-Ylänne, S. \& Katajavuori, N. 2010. Relationships between 
students' approaches to learning, perceptions of the teaching-learning environment, and study success: a case study of third-year veterinary students. Journal of Veterinary Medical Education 37: 282-288.

Ryan, M.T., Irwin, J.A., Bannon, F.J., Mulholland, C.W. \& Baird, A.W. 2004. Observations of veterinary students' approaches to study in pre-clinical years. Journal of Veterinary Medical Education 31: 242-254.

Salomäki, T., Laakkonen, J. \& Ruohoniemi, M. 2014. Students as teachers in an anatomy dissection course. Journal of Veterinary Medical Education 41: 60-67.

Strand, E.B., Zaparanick, T.L., Brace, J.J. 2005. Quality of life and stress factors for veterinary medical students. Journal of Veterinary Medical Education 32: 182-192.

Sutton, R.C. 2007. Veterinary students and their reported academic and personal experiencies during the first year of veterinary school. Journal of Veterinary Medical Education 34: 645-651.

Thurman, J., Volet, S.E., Bolton, J.R. 2009. Collaborative, case-based learning: how do students actually learn from each other? Journal of Veterinary Medical Education 36: 297-304.

Tuominen-Soini H., Salmela-Aro, K., Niemivirta M. 2012. Achievement goal orientations and academic well-being across the transition to upper secondary education. Learning and Individual Differences 22: 290-305.

Tötemeyer, S., Dobbs, H., Rutland, C.S. 2012. What is it like to be an international student at veterinary school? Perception and performance in first year - a case study at a UK veterinary school. Journal of Veterinary Medical Education 39: 180-188.

Yorke, M. 2000. The quality of the student experience: what can institutions learn from data relating to non-completion? Quality in Higher Education 6: 61-75.

Vermunt, J.D.H.M. \& Verloop, N.1999. Congruence and friction between learning and teaching. Learning and Instruction 9: 257-280.

Vermunt, J.D.H.M. \& Verloop, N. 2000. Dissonance in students' regulation of learning processes. 
European Journal of Psychology of Education 15: 75-87, 2000.

Williams, S.M., Arnold, P.K., Mills, J.N. et al. 2005. Coping with stress: a survey of Murdoch University veterinary students. Journal of Veterinary Medical Education 32: 201-212.

Table 1. Comparison on the levels of self-reported stress and, statements on time management and learning strategy between first and third year students.

\begin{tabular}{|c|c|c|c|c|}
\hline & \multicolumn{2}{|c|}{$\begin{array}{l}\text { First study } \\
\text { year } \\
(n=45)\end{array}$} & \multicolumn{2}{|c|}{$\begin{array}{l}\text { Third study } \\
\text { year } \\
(n=46)\end{array}$} \\
\hline EXPERIENCED STRESS & Mean & SD & Mean & SD \\
\hline Subjective stress experience (1 item) & 2.89 & 1.09 & 3.96 & 1.05 \\
\hline Stress related to studies (sum variable) & 2.77 & 0.88 & 3.12 & 0.71 \\
\hline Concurrent courses & 2.33 & 1.13 & 3.47 & 1.31 \\
\hline Demanding learning goals of the courses & 3.07 & 1.12 & 3.80 & 1.06 \\
\hline A new subject matter & 2.98 & 1.27 & 2.73 & 1.12 \\
\hline Fear of attaining a low grade & 2.73 & 1.14 & 2.47 & 1.16 \\
\hline Stress factor unrelated to studies & 2.20 & 1.27 & 3.07 & 1.18 \\
\hline SELF-REGULATION OF LEARNING & & & & \\
\hline Self-monitoring of learning & 2.93 & 0.85 & 3.32 & 0.67 \\
\hline
\end{tabular}




\begin{tabular}{|r|l|l|l|l|}
\hline $\begin{array}{r}\text { I adhere to certain schedule in order to learn the } \\
\text { topics }\end{array}$ & 3.09 & 0.95 & 3.33 & 0.85 \\
$\begin{array}{r}\text { I adhere to my study schedule } \\
\text { I work hard even if I don't like all the topics and } \\
\text { demands of the course }\end{array}$ & 3.47 & 1.06 & 2.87 & 0.82 \\
\hline $\begin{array}{r}\text { Persistency } \quad \text { I have no difficulties in striving to } \\
\text { complete the less interesting study tasks. }\end{array}$ & 2.93 & 1.03 & 3.00 & 0.92 \\
$\begin{array}{r}\text { I often give up when I'm studying difficult } \\
\text { topics/issues and focus on the easier ones. }\end{array}$ & 2.60 & 1.14 & 2.22 & 0.94 \\
$\begin{array}{r}\text { I use the time that I have reserved for } \\
\text { studying efficiently. }\end{array}$ & 3.20 & 0.87 & 3.09 & 0.92 \\
$\begin{array}{r}\text { Reflection on learning } \\
\text { After a study attainment I reflect what I've }\end{array}$ & 2.99 & 0.79 & 3.01 & 0.65 \\
$\begin{array}{r}\text { learned and how I could improve my learning. } \\
\text { Itry to accommodate my own style of studying to } \\
\text { match the requirements of each course. }\end{array}$ & 2.51 & 0.89 & 2.59 & 0.86 \\
$\begin{array}{r}\text { After the course I contemplate how I succeed and } \\
\text { how I can improve my performance. }\end{array}$ & 3.28 & 1.14 & 3.09 & 0.96 \\
\hline
\end{tabular}


Table 2. Comparison of the three-factor solution (Principal Axis factoring, Varimax rotation) for the self-regulation of learning for the two stages of the study (the factor loadings of third study year in brackets).

\begin{tabular}{|c|c|c|c|}
\hline Items & F1 & F2 & F3 \\
\hline \multicolumn{4}{|l|}{ Self-monitoring } \\
\hline $\begin{array}{l}\text { I adhere to certain schedule in order to learn the } \\
\text { topics }\end{array}$ & $\begin{array}{l}.854 \\
(.859)\end{array}$ & & \\
\hline I adhere to my study schedule & $\begin{array}{l}.769 \\
(.804)\end{array}$ & & \\
\hline $\begin{array}{l}\text { I work hard even if I don't like all the topics and } \\
\text { demands of the course }\end{array}$ & $\begin{array}{l}.682 \\
(.418)\end{array}$ & $\begin{array}{l}.130 \\
(.402)\end{array}$ & \\
\hline $\begin{array}{l}\text { I try to accommodate my own style of studying so } \\
\text { that it would match with the requirements of each } \\
\text { course. }\end{array}$ & $\begin{array}{l}.457 \\
(.169)\end{array}$ & $\begin{array}{l}.306 \\
(.252)\end{array}$ & $\begin{array}{l}.135 \\
(.422)\end{array}$ \\
\hline \multicolumn{4}{|l|}{ Persistency } \\
\hline $\begin{array}{l}\text { I have no difficulties in striving to complete the less } \\
\text { interesting study tasks. }\end{array}$ & $(.443)$ & $\begin{array}{l}.834 \\
(.635)\end{array}$ & \\
\hline $\begin{array}{l}\text { I use the time that I have reserved for studying } \\
\text { efficiently. }\end{array}$ & .307 & $\begin{array}{l}.632 \\
(.688)\end{array}$ & \\
\hline $\begin{array}{l}\text { I often give up when I'm studying difficult } \\
\text { topics/issues and focus on the easier ones. }\end{array}$ & -.134 & $\begin{array}{l}-.473 \\
(-.311)\end{array}$ & .166 \\
\hline \multicolumn{4}{|l|}{ Reflection on learning } \\
\hline $\begin{array}{l}\text { After a study attainment I reflect what I've learned } \\
\text { and how I could improve my learning. }\end{array}$ & .329 & $(-.199)$ & $\begin{array}{l}.844 \\
(.822)\end{array}$ \\
\hline $\begin{array}{l}\text { After the course I contemplate how I succeed and } \\
\text { how I can improve my performance. }\end{array}$ & & & $\begin{array}{l}.469 \\
(.545)\end{array}$ \\
\hline
\end{tabular}


Table 3. Spearman's correlations $\left(\mathrm{r}^{\mathrm{s}}\right)$ between prior university level studies, subjective stress experience, study stress and self-regulation of learning at first study year.

\begin{tabular}{|l|c|c|c|c|c|}
\hline & 2. & 3. & 4. & 5. & 6. \\
\hline 1. Prior university level studies & $-.32 *$ & $-.30^{*}$ & -.18 & $.30^{*}$ & .07 \\
\hline 2. Subjective stress experience & & $.62 * *$ & .09 & -.26 & -.25 \\
\hline 3. Study stress & & & .06 & $-.56^{* *}$ & -.08 \\
\hline 4. Self-monitoring of learning & & & & .16 & .26 \\
\hline 5. Persistency & & & & & .05 \\
\hline 6. Reflection on learning & & & & & \\
\hline
\end{tabular}


Table 4. Spearman's correlations $\left(\mathrm{r}_{\mathrm{s}}\right)$ between prior university level studies, subjective stress experience, study stress and self-regulation of learning at third study year.

\begin{tabular}{|l|l|l|l|l|l|}
\hline & 2. & 3. & 4. & 5. & 6. \\
\hline 1. Prior university level studies & .17 & -.18 & -04 & .17 & $.35^{*}$ \\
\hline 2. Subjective stress experience & & $.38^{*}$ & .10 & -.27 & .22 \\
\hline 3. Study stress & & & .19 & -.21 & $.39^{* *}$ \\
\hline 4. Self-monitoring of learning & & & & $.30^{*}$ & .23 \\
\hline 5. Persistency & & & & & .12 \\
\hline 6. Reflection on learning & & & & & \\
\hline
\end{tabular}

